\title{
Identification of Author Profiles Through Social Networks
}

\section{Autores}

Jesús Silva, Nicolas Elias Maria Santodomingo, Ligia Romero, Marisol Jorge, Maritza Herrera, Omar Bonerge Pineda Lezama, Francisco Javier Echeverry.

\begin{abstract}
The aim of this paper is to compile dictionaries of slang words, abbreviations, contractions, and emoticons to help the pre-processing of texts published in social networks. The use of these dictionaries is intended to improve the results of the tasks related to data obtained from these platforms. Therefore, a hypothesis was evaluated in the task of identifying author profiles (author profiling).
\end{abstract}

Palabras clave

Lexicon, Social networks, Author profiling, Text classification 